\title{
A Circularity-based Planning Approach for Construction and Demolition (C\&D) Waste Management: A Case Study of Malaysia
}

\author{
Mohd Reza Esa $^{1,2}$, Anthony Halog ${ }^{1}$, Jafri Zulkepli ${ }^{3}$, Lucia Rigamonti $^{4}$ and Shazwan Mohamed Shaari ${ }^{2}$ \\ ${ }^{1}$ School of Earth and Environmental Sciences, the University of Queensland, Australia, \\ ${ }^{2}$ Faculty of Architecture, Planning and Surveying, Universiti Teknologi MARA, Shah Alam, Selangor, Malaysia, \\ ${ }^{3}$ School of Quantitative Sciences, College of Arts and Sciences, Universiti Utara Malaysia, Malaysia, \\ ${ }^{4}$ Department of Civil and Environmental Engineering - Environmental Section, Politecnico di Milano.
}

\begin{abstract}
In recent years, Malaysia has faced an intense demand for infrastructure development and the construction industry has become an integral part of transforming the country into a developed nation. Large numbers of development works are perturbing and they are subject to the improper management of construction and demolition (C\&D) wastes. Lacking in methods for managing C\&D wastes throughout the construction cycle has jeopardized the effort to preserve the environment. Circular economy (CE) was used as a basis to improve the C\&D waste management system in Malaysia. We have developed a circularitybased planning approach to managing the wastes with an idea to maximize the resources. We collected the feedback from the construction actors in Malaysia to identify the suitable 3R principles of reduce, reuse and recycle and waste minimization strategies to be adopted throughout the construction cycle. Based on the feedbacks, we introduced a circularity-oriented framework of C\&D waste management that could be applied throughout the construction cycle. Then, we tested the effectiveness of the framework by conducting a simulation process using system dynamics modelling. The results revealed that the waste generation could be significantly reduced - that indirectly mitigate the environmental impacts.
\end{abstract}

\section{Introduction}

The construction industry has a multiplier effect, with a lot of other industries relying on construction for their growth and business [1]. High demand for construction materials will influence the expanding of the manufacturing industry. Today, the Malaysian construction industry is moving rapidly due to urbanization elements that contribute to the increasing demand for improved infrastructure facilities. The scales of the project inevitably generate more $C \& D$ wastes. Due to limited regulation and guidelines, there are a large amount of C\&D wastes being disposed of illegally and put pressure on the government to preserve the environment. The construction industry obviously created substantial impacts on the environment [2-3]. The $3 \mathrm{R}$ principles of reduce, reuse and recycle have not been fully utilized in Malaysia to manage C\&D wastes.

We tackled the issues of the increasing amount of C\&D wastes by identifying the importance of developing a C\&D waste management system that is useful to be implemented throughout the construction cycle. The emergence of the Circular Economy (CE) has attracted our interest to explore its potential to be used as a basis for developing a circular approach for C\&D waste management [4-5]. CE provides a new paradigm to the construction industry to conceive a sustainable future [6]. CE encourage the idea of 'doing less with less' to maximize the natural resources and preserve the environment by integrating the $3 \mathrm{R}$ principles during its implementation [7]. The 3R principles should be fully utilized in a country like Malaysia where the adoption of technology that could minimize the waste generated is very difficult. In Malaysia, a labour intensive method is being preferred by most of the construction actors [8-9]. This method is identified as one of the factors that contribute to the waste generation. Therefore, it is necessary to start patrolling the waste generation at the initial stage of the construction cycle. When the priority is given to control the waste generation as early as possible, the generated wastes could be managed to its suitability; either being reused or recycled.

Waste minimizations strategies vary depending on its capacity to be implemented in various stages of the construction cycle. The evolutionary of construction method provides the opportunity to replace the labour intensive method among construction actors [10-11]. A commitment to environmental sustainability motivates the construction actors to develop better C\&D waste management [9]. Similarly, the awareness in protecting the environment has shifted the direction of the government to enhance the regulations related to $C \& D$ waste management [12]. Revising regulations enforce the construction actors to shift the mindset to prioritize

* Corresponding author: author@e-mail.org 
the management of $\mathrm{C} \& \mathrm{D}$ wastes. The waste management plan, which effectively minimizes waste generation [13], significantly identifies the relationship of the sources of wastes in various construction stages [10]. The plan would definitely help the construction actors to prepare action policies.

In this study, we proposed a circularity-based planning approach of waste management combining both quantitative and qualitative methods, examined the diversities of C\&D waste management and the relationship of $3 R$ principles among the waste minimization strategies, and explicitly outlined its suitability to be adopted in the Malaysian construction industry. In addition, we modelled and simulated the outcomes for measuring its effectiveness to reduce wastes.

\section{Research Methods}

\subsection{Delphi method and AHP}

A three round of web-based survey was employed in which AHP was incorporated in Round 2. We employed this method due to its flexibility that allows the expert to modify their preferences until all of them agreed and also obtain more reliable and objective results. The experts were selected among the developers, government agencies, consultants and contractors; based on their knowledge and experience related to $\mathrm{C} \& \mathrm{D}$ waste management in Malaysia. In Round 1, 25 experts were responded to the survey; however, after the screening process, only 20 were selected to proceed to the next round. All selected experts were consistently involved in the survey until Round 3 except one expert who has to withdraw due to high workload. In Round 1, the experts are required to respond the questions related to $C \& D$ waste management and multiple frequencies analysis was employed to analyse the result. From the compiled result, a hierarchy of $\mathrm{C} \& \mathrm{D}$ waste management was developed and AHP was used in Round 2 to help the experts to decide the most suitable strategies to be adopted in the Malaysian construction industry. Finally, in Round 3, a 60\% level of consensus is required from all the experts to finalize the results.

\subsection{Distribution of Questionnaire}

The questionnaire is divided into four sections including General Information, Influencing Factors of Waste Generation, Waste Minimization Strategy and General Comments. The sample population was randomly selected among the developers, government agencies, consultants and contractors in Malaysia. We calculated the sample size to plan and interpret the results derived from the distribution of questionnaires [14]. From the calculation, 385 sample sizes are needed, however, we distributed 480 questionnaires in Malaysia using three ways; posted, circulated and invited to the web-based survey. 167 questionnaires were returned after three months. The returned questionnaires were then analysed using the Statistical Package for the Social Sciences
(SPSS). Table 1 demonstrates the statistical analyses that were adopted in analysing the questions in each section of the questionnaire.

\subsection{System dynamic methodology}

C\&D waste management is a highly complex and dynamic scenario in which involved a lot of variables. The application of system dynamic methodology will create a better understanding of the complexities of C\&D waste management [16]. including the stakeholders, strategies, principles etc.; to understand the whole process of managing the $C \& D$ wastes [15]. In this method, we need to identify the main problem of C\&D waste management. After the problem has been identified, the key variables to be included in the model were finalized. The time horizon was determined to run the model as well. We identified the key system feedbacks and system archetypes to develop a CLD. The developed CLD was then being formulated into a SFD to underline the relationship among the variables. The variables were being formulated by setting parameter values before conducting the validation processes. We tested the model using the suitable testing procedures to verify the efficiencies of the model to overcome the problems. Finally, we evaluated the model by applying different policies to see what it might affect the model.

Table 1. Statistical analysis of the questionnaire

\begin{tabular}{|l|l|l|}
\hline Test & \multicolumn{1}{|c|}{ Description } & \multicolumn{1}{c|}{ Application } \\
\hline Percentage & $\begin{array}{l}\text { A normal percentage was } \\
\text { used to determine the } \\
\text { ranking. }\end{array}$ & $\begin{array}{l}\text { Section I - Q1 to Q8 } \\
\text { Section III - Q1 and } \\
\text { Q2 }\end{array}$ \\
\hline Descriptive & $\begin{array}{l}\text { The mean values of the } \\
\text { variables were determined } \\
\text { in order to rank the } \\
\text { variables. }\end{array}$ & $\begin{array}{l}\text { Section I - Q9 } \\
\text { Section II - Q1 } \\
\text { Section III - Q3, Q4, } \\
\text { Q5 }\end{array}$ \\
\hline $\begin{array}{l}\text { Kruskal- } \\
\text { Wallis } H\end{array}$ & $\begin{array}{l}\text { Analysis of testing } \\
\text { simultaneously any } \\
\text { significant differences } \\
\text { between two or more group } \\
\text { of respondents. }\end{array}$ & $\begin{array}{l}\text { Section III - Q3, Q4, } \\
\text { Q5 }\end{array}$ \\
\hline Mann- & $\begin{array}{l}\text { Similarly with Kruskal- } \\
\text { Wallis H test, but only focus } \\
\text { on testing any significant } \\
\text { difference between two } \\
\text { groups of respondents only } \\
\text { at a time. }\end{array}$ & $\begin{array}{l}\text { Section III - Q3, Q4, } \\
\text { Q5 }\end{array}$ \\
\hline Reliability & $\begin{array}{l}\text { The reliability test on the } \\
\text { Likert scale used in this } \\
\text { study in which the values } \\
\text { range from 0 to 1, higher } \\
\text { values indicate greater } \\
\text { reliability. }\end{array}$ & $\begin{array}{l}\text { Section III - Q3, Q4, } \\
\text { Q5 }\end{array}$ \\
\hline $\begin{array}{l}\text { A data reduction technique } \\
\text { whereas the variables could } \\
\text { be grouped together or } \\
\text { eliminate altogether in order } \\
\text { to produce a more } \\
\text { manageable variable. }\end{array}$ & $\begin{array}{l}\text { Section III - Q3, Q4, } \\
\text { Q5 }\end{array}$ \\
\hline
\end{tabular}

\section{Results}

The designed theoretical framework for C\&D waste management used a three-layer approach of micro, meso and macro of $\mathrm{CE}$. At the micro level, the waste reduction 
strategy should be employed during the planning and designing stage. Wastes can be controlled by implementing a modern construction method, integrating the standardization elements, selecting proper materials and awarding the organizations that put initiatives to reduce waste as early as possible. At the meso level, the regulation should be revised to promote the usage of reuse and recycle materials. The encouragement should be given to adapt an eco-industrial park development. Procedures of sorting out the wastes should be emphasized at this level. Wastes were generated more at the construction and demolition stage which is under the macro level [9]. Site management should be enhanced by properly storing the on-site materials to avoid faulty materials. The attitudes of the workers should be monitored as bad workmanship is identified as one of the factors that contribute to the waste generation [17]. All construction actors including the clients, consultants and contractors should work and communicate closely to prioritize C\&D waste management.

The developed theoretical framework was then being validated to ensure its suitability to be adopted in the Malaysian construction industry. A combination of the Delphi method and Analytical Hierarchy Process
(AHP) was employed to seek experts' opinions among the Malaysian construction actors. The outcome is the introduction of a circularity-oriented framework of C\&D waste management that was developed based on the concept of $\mathrm{CE}$ as shown in Fig. 1. The results revealed that most of the waste minimization strategies included are suitable to be implemented in Malaysia. However, the experts were concerned about the limited number of recycling facilities and suggested it should be increased to promote the recycling mechanism. Government agencies and consultants are the responsible organizations to ensure the implementation of C\&D waste management at the planning and designing stage and procurement stage respectively. At the construction and demolition stage, contractors and consultants are the responsible organizations.

Key components in the framework as shown in Fig. 1 is the selected $3 \mathrm{R}$ principles and waste minimization strategies. The relationships between these components are complex and dynamic. The framework was then being transformed into a model in the form of Causalloop Diagram (CLD) to study its complexities and dynamics relationship.

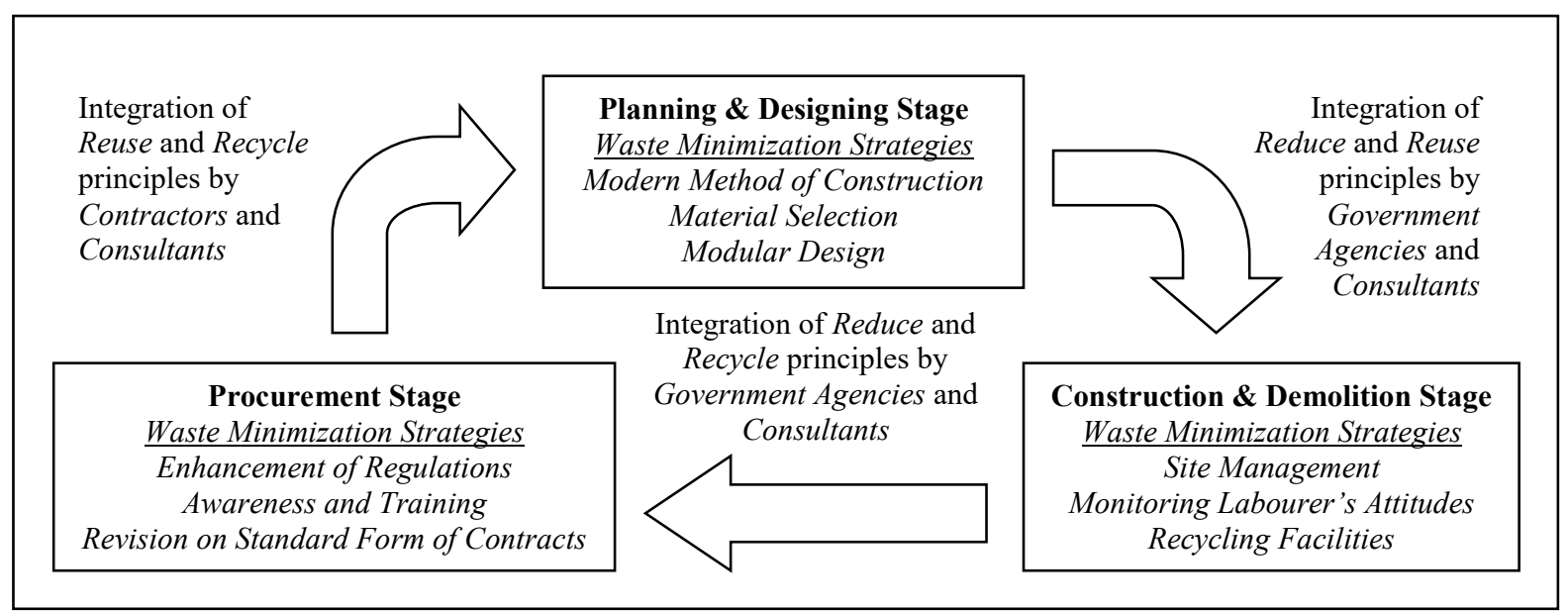

Fig. 1. A circularity-oriented framework of C\&D waste management in Malaysia

Fig. 2 exhibits the CLD that consisted of five causal loops under three components; demand and supply sector, construction, waste generation and processed waste sector, and waste reduction strategies. Population growth will produce a direct effect on basic needs such as housing and infrastructure development. When the demand is increased, the increment in the level of supply will also follow. There are many developments works in Malaysia to achieve their target to become a high-income nation by 2050 [1]. This national agenda will put pressure on the environmental aspects as the amount of wastes will be increased as well. The inefficient management of waste will pressurize the landfill and influence the illegal dumping activities. Therefore, waste reduction strategies should be employed to control the waste generation such as modern construction method, modular design, material selection etc. Stock-flow diagram (SFD) was derived based on the developed CLD in Fig. 2 to simulate the effectiveness of C\&D waste management to reduce waste generation. SFD was formulated using Vensim software to demonstrate more detailed processes by analysing the model quantitatively as shown in Fig. 3. Three policies were adopted to predict the outcomes of the model. These policies are the enhancement of reuse and recycle construction material, modern construction method and monitoring and creating awareness among workers. The results indicated that the policies are complimented to each other and could effectively reduce $12 \%$ of C\&D wastes. 


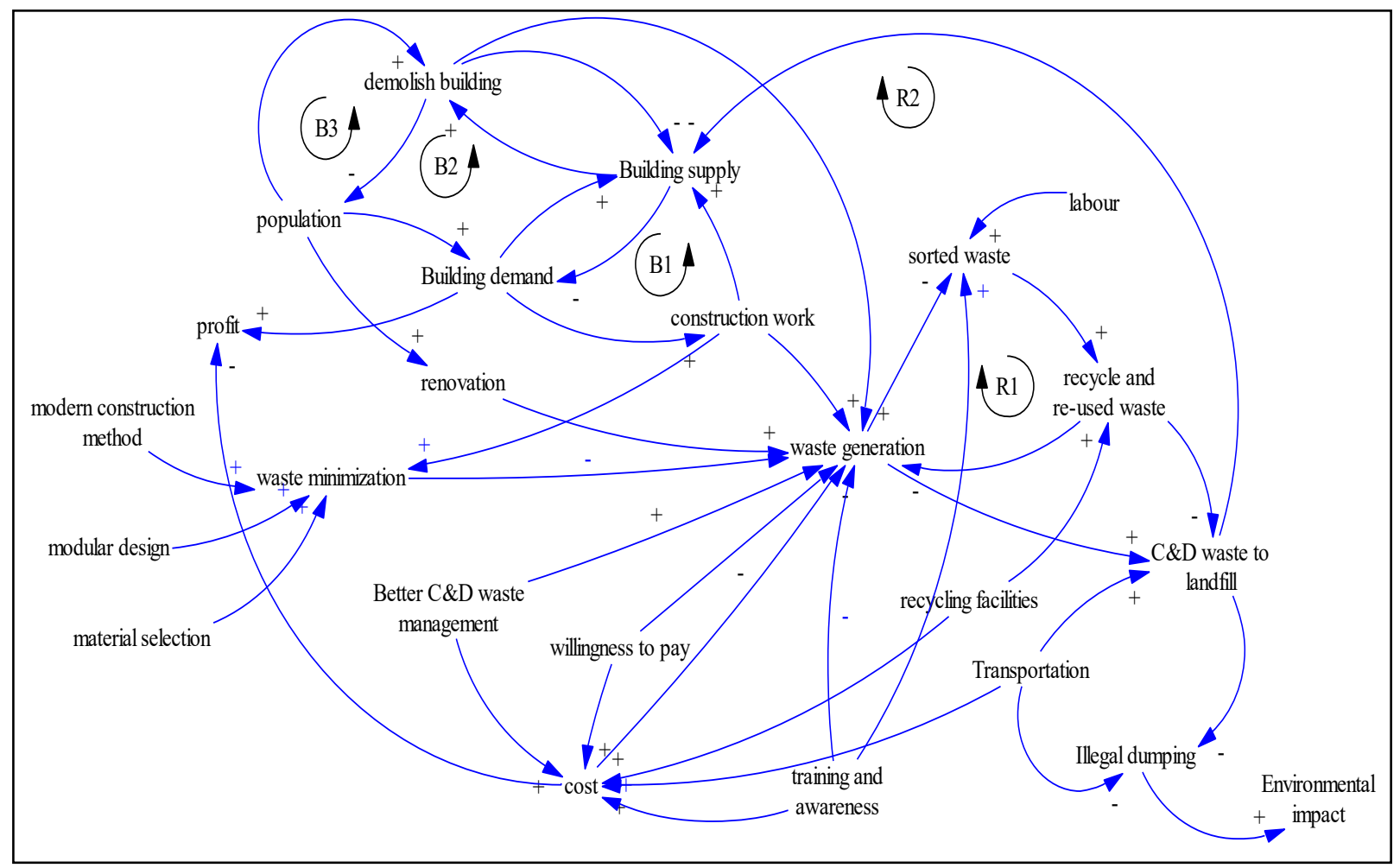

Fig. 2. CLD of C\&D waste management

\section{Discussions}

The $3 R$ principles of 'reduce, reuse and recycle' should be considered in developing a more circular approach of C\&D waste management throughout the construction cycle. The idea to reduce waste generation should be prioritized as early as possible. For instance, a more environmentally-friendly development works should be adopted by considering the integration of $3 \mathrm{R}$ principles at the beginning of the construction cycle. The concept of $\mathrm{CE}$, which prioritizing the idea of 'turning the waste into wealth'; has been identified as a suitable approach and was used as a basis for a better C\&D wastes management in this study.

The extent of successful reduction of the waste generation throughout the construction cycle is reflected in the ability to select the most suitable waste minimization strategies. At the planning and designing stage, the implementation of a modern construction method was revealed to be the most appropriate strategy to reduce waste generation. Meanwhile, the finding has also highlighted the significance of regularly conducting awareness and training programmes on waste management among construction actors at the procurement stage. Finally, for the construction and demolition stage, the finding shows that the most suitable strategy is the importance of having effective site management to control the waste generation.
Urbanization has increased the demand for housing and infrastructure development in which indirectly will influence the increasing amount of C\&D wastes. The simulation process has provided the platform to simulate the impact of waste generation and the consequences of the generated waste if no proper action is taken. In the simulation process, the model was divided into five subsectors; demand and supply of building, construction work, C\&D wastes generation, C\&D wastes processed and policy implementation. The reliability of the model was tested using structural validity test and behavioural validity test. The results revealed that the model is reliable and suitable to be used as a benchmark for the construction actors to find ways of reducing the waste generation. Even though there is a lack of historical data related to the Malaysian construction industry in this model, the assumptions made were close enough to the real-case scenario.

In conclusion, a circularity-based planning approach of C\&D wastes management was developed by employing the CE approach as a core in this study. This study as well as extended the knowledge on the importance of developing systematic C\&D waste management that is applicable throughout the construction cycle. Moreover, suitable waste minimization strategies should be selected properly according to its significance at each stage of the construction cycle, whereas the responsible organizations should ensure its implementation. 


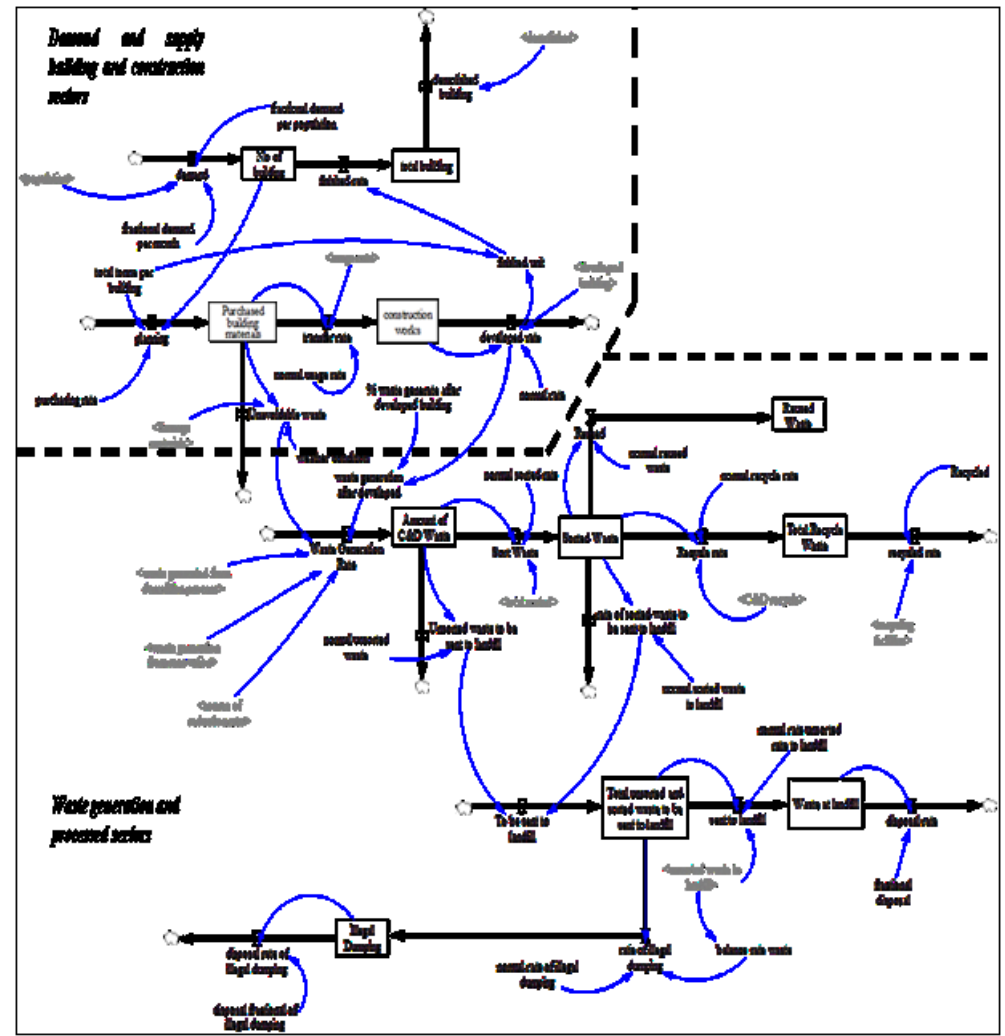

Fig. 3. A stock-flow diagram

\section{References}

1. CIDB. Construction Industry Transformation Plan (CITP) 2016-2020. 2015.

2. Low, S.P., S. Gao, and Y.L. See, Strategies and measures for implementing eco-labelling schemes in Singapore's construction industry. Resources, Conservation and Recycling, 2014. 89(0): p. 31-40.

3. Udawatta, N., J. Zuo, K. Chiveralls, and G. Zillante, Improving waste management in construction projects: An Australian study. Resources, Conservation and Recycling, 2015. 101(0): p. 73-83.

4. Kiser, B., CIRCULAR ECONOMY Getting the circulation going. Nature, 2016. 531(7595): p. 443-444.

5. Qian, G. and C. Wang, Circular Economy Cities, in China's Eco-city Construction. 2016, Springer. p. 169-188.

6. Cahalane, C. Construction industry needs a circular economy for a sustainable future. 2014 [cited 201420 November]; Available from: http://www.theguardian.com/sustainablebusiness/construction-industry-circulareconomy.

7. Dajian, Z., Towards a Closed-Loop Materials Economy. Chinese Journal of Population Resources and Environment, 2004. 2(1): p. 912.

8. Akhir, N.S.M., I.A. Rahman, A.H. Memon, and S. Nagapan. Factors of Waste Generation throughout Construction Life Cycle. in
Malaysian Technical Universities Conference on Engineering \& Technology (MUCET). 2013. Kuantan, Pahang.

9. Esa, M.R., A. Halog, and L. Rigamonti, Strategies for minimizing construction and demolition wastes in Malaysia. Resources, Conservation and Recycling, 2017. 120.

10. Gangolells, M., M. Casals, N. Forcada, and M. Macarulla, Analysis of the implementation of effective waste management practices in construction projects and sites. Resources, Conservation and Recycling, 2014. 93(0): p. 99-111.

11. Lachimpadi, S.K., J.J. Pereira, M.R. Taha, and M. Mokhtar, Construction waste minimisation comparing conventional and precast construction (Mixed System and IBS) methods in high-rise buildings: A Malaysia case study. Resources, Conservation and Recycling, 2012. 68: p. 96-103.

12. Arif, M., D. Bendi, T. Toma-Sabbagh, and M. Sutrisna, Construction waste management in India: an exploratory study. Construction Innovation: Information, Process, Management, 2012. 12(2): p. 133-155.

13. Wang, J.Y., X.P. Kang, and V. Wing-Yan Tam, An investigation of construction wastes: an empirical study in Shenzhen. Journal of Engineering, Design and Technology, 2008. 6(3): p. 227-236.

14. Smith, S. Determining Sample Size: How to Ensure You Get the Correct Sample Size. 2013 [cited 201618 August 2016]; Available from:

*Corresponding author: author@e-mail.org 
https://www.qualtrics.com/blog/determiningsample-size/.

15. Hao, J.L., M.J. Hills, and T. Huang, $A$ simulation model using system dynamic method for construction and demolition waste management in Hong Kong. Construction Innovation: Information, Process, Management, 2007. 7(1): p. 7-21.

16. Jian Li, H., M.J. Hill, and S. Li Yin, Managing construction waste on-site through system dynamics modelling: the case of Hong Kong. Engineering, Construction and Architectural Management, 2008. 15(2): p. 103-113.

17. Kulatunga, U., D. Amaratunga, R. Haigh, and R. Rameezdeen, Attitudes and perceptions of construction workforce on construction waste in Sri Lanka. Management of Environmental Quality: An International Journal, 2006. 17(1): p. 57-72. 